\title{
Descubrimiento de varios fragmentos de una Biblia hebrea (Calahorra, s. XIV)
}

\author{
Manuel Hernández Sigüenza* \\ Universidad Eclesiástica San Dámaso - Extensión de Logroño \\ ORCID ID: https://orcid.org/0000-0003-0963-6614
}

El objetivo de este estudio es poner de manifiesto el hallazgo fortuito de cuatro fragmentos de una Biblia hebrea, presumiblemente del s. XIV, en la ciudad riojana de Calahorra. Dichos fragmentos forman parte del libro de Ester y servían de encuadernación a un libro de la cofradía de Santiago y san Andrés, parroquias calagurritanas.

Asimismo, a mediados del siglo pasado se encontraron dos folios manuscritos del libro del Éxodo perteneciente a otra Biblia hebrea (s. XIV). Si bien se llegaron a confirmar los pasajes, no se realizó un estudio pormenorizado de ambos folios.

Sin duda, estos descubrimientos en el mismo archivo parroquial, sito en la antigua judería de Calahorra, son nuevas pruebas que atestiguan la fuerte presencia judía en la ciudad riojabajeña.

Palabras Clave: Calahorra; siglo XIv; Libro de Ester; Biblia hebrea; fragmentos.

The Discovery of Several Fragments from a Hebrew Bible (Calahorra, 14th Century).- The aim of this paper is to show the accidental discovery of four fragments from a Hebrew Bible, presumably dated from 14th Century, in the Riojan city of Calahorra. Those fragments are part of the Book of Esther and served as binding of a Santiago and saint Andrés brotherhood book, Calagurritan parishes.

Moreover, in the middle of the last century two manuscript pages of the Book of Exodus belonging to another Hebrew Bible (14th Century) were found. Although the passages became proved, a detailed study of both pages was not done.

Doubtlessly, these discoveries in the same parish archive located in the ancient Jewish quarter of Calahorra are new proofs that bear witness to the strong Jewish presence in the lower Riojan city.

KeYwords: Calahorra; 14th Century; Book of Esther; Hebrew Bible; Fragments.

\footnotetext{
*mahesi_93@hotmail.com
}

Copyright: (C) 2021 CSIC. Este es un artículo de acceso abierto distribuido bajo los términos de la licencia de uso y distribución Creative Commons Reconocimiento 4.0 Internacional (CC BY 4.0). 


\section{Una APROXIMACión A la COMUNidAD JUdía de CALAhORRA}

En la Baja Edad Media, la bimilenaria ciudad de Calahorra se dividía en los barrios de Suso, parte alta de la localidad ubicada sobre dos colinas, y Yuso, zona baja en la que se incluía la catedral. Es, precisamente, en la colina o Quiñón de san Andrés del barrio de Suso donde se asentaba la judería ${ }^{1}$. Ocupaba la parte más alta de la ciudad y estaba situada junto al castillo medieval; lugar en el cual se ubicaba la acrópolis en época romana. Rodeada de murallas, E. Cantera la define como «una auténtica ciudadela dentro de la propia ciudad de Calahorra» ${ }^{2}$.

Sin lugar a dudas, se trataba de una de las juderías más importantes de la zona, junto con las de Tudela o Haro. Por los documentos conservados en el archivo catedralicio, se conoce que poseían hornos propios, carnicerías que vendían productos conforme a la religión judía, un osario o cementerio, una sinagoga... De hecho, constituían una aljama ${ }^{3}$, gozando de una estructura social, judicial y religiosa distinta del resto de la ciudad; aunque a comienzos del s. XIV, «los judíos gozaron durante mucho tiempo de una completa igualdad jurídica respecto a la población cristiana» ${ }^{4}$.

Los judíos se dedicaron ${ }^{5}$ al comercio, actividades de intercambio en Calahorra y en villas próximas, actividades artesanales, tareas agrícolas destacando el cultivo de huertas y viñas, la medicina, arrendamiento de rentas del cabildo de la catedral... En este sentido, fueron habituales los litigios y conflictos entre el cabildo y los judíos. Esto es indicativo del

${ }^{1}$ Para una información más exhaustiva sobre los orígenes, desarrollo y vida de la judería calagurritana en el bajomedievo, $c f$. Francisco CANTERA Burgos, «La judería de Calahorra», Sefarad 15 (1955) págs. 353-372 y «La judería de Calahorra», Sefarad 16 (1956) págs. 73-112, y Enrique Cantera Montenegro, Las juderías de la diócesis de Calahorra en la Baja Edad Media (Logroño: Instituto de Estudios Riojanos, 1987) págs. 515-574.

${ }^{2}$ Cf. Cantera Montenegro, Las juderías de la diócesis de Calahorra, pág. 518.

3 Cf. Cantera Montenegro, Las juderías de la diócesis de Calahorra, pág. 520.

${ }^{4}$ Cf. Cantera Montenegro, Las juderías de la diócesis de Calahorra, pág. 529.

5 Para mayor información sobre las actividades y profesiones desempeñadas por los hebreos, vid. Enrique Cantera Montenegro, «Actividades socio-profesionales de la población hebrea en Calahorra», en Calahorra: Bimilenario de su fundación. Actas del I Symposium de Historia de Calahorra (Madrid: Ministerio de Cultura, 1984) págs. 351-358. 
potencial económico y de la prosperidad material de que disponía la comunidad hebrea a finales del s. XV. El papel desempeñado por los judíos fue esencial para el desarrollo de la actividad económica, puesto que tenían una función primordial en prácticamente todas las facetas de la misma.

De acuerdo con H. Beinart ${ }^{6}$, en los ss. XIII-XIV, los de mayor bonanza, la población hebrea llegó a alcanzar los 400 habitantes. Asimismo, a pesar de los movimientos antisemitas en la última década de 1300, a finales del s. XV inmediatamente antes del Decreto de Expulsión, la comunidad estaba compuesta por unos 350-400 individuos. Por su parte, E. Cantera ${ }^{7}$ afirma que antes de ser expulsados la población hebrea fue de 500 personas, constituyendo el $15 \%$ de los habitantes totales de Calahorra. Sea cual fuere el número preciso, es de notar la fuerte presencia e influencia de la judería calagurritana respecto a sus correspondientes vecinas en la España septentrional.

A lo largo del s. XV crecieron las tensiones entre judíos y cristianos, especialmente motivadas por razones económicas, llegando al punto de la expulsión. El 31 de marzo de 1492 en los reinos de Castilla y Aragón se decretó la expulsión general de los judíos, teniendo un plazo de cuatro meses para abandonar dichas tierras. En Calahorra ${ }^{8}$ la expulsión fue llevada a cabo el 31 de julio de 1492. Al disponer de tan poco tiempo para vender sus bienes inmuebles, los judíos en general obtuvieron un precio notablemente inferior al valor real. En lo que respecta a otras posesiones, E. Cantera afirma:

Los judíos recibieron también autorización para llevarse todos sus bienes muebles, con la única excepción de oro, plata, moneda amonedada, armas y caballos, cuya salida estaba prohibida de forma terminante en todos los reinos de la Edad Media ${ }^{9}$.

${ }^{6}$ Cf. Haim BeInART y Yom-Tov Assis, «Calahorra», en Encyclopaedia Judaica, ed. Fred SkoLNIK, vol.4 (Detroit: Thomson Gale, 1972) págs. 349-350.

7 Cf. Enrique Cantera Montenegro, «Los últimos tiempos de la presencia judía en Calahorra y La Rioja», Kalakorikos 10 (2007) págs. 57-86: 58.

8 Cf. Eliseo SÁInz RIPA, Sedes episcopales de La Rioja. Siglos XIV-XV, vol. 2 (Logroño: Diócesis de Calahorra y La Calzada-Logroño, 1995) pág. 126.

9 Cf. Cantera Montenegro, «Los últimos tiempos de la presencia judía en Calahorra y La Rioja», pág. 71. 
Si bien muchos judíos se fueron, algunos permanecieron como nuevos conversos. Los nuevos cristianos fueron diseminados por la ciudad; mientras que la judería comenzó a ser habitada por los viejos. No obstante, en los años inmediatos al decreto no se volvería a ocupar, tiempo que aprovechó el cabildo para edificar ciertas dependencias eclesiales como las ermitas de san Salvador y san Sebastián ${ }^{10}$.

Este decreto de expulsión permitía a los judíos llevar consigo sus libros sagrados. Razón de más sabiendo que fueron expulsados, entre otros motivos, por religión. Por ende, no deja de ser significativo el porqué se hizo uso de varias páginas de Biblias hebreas como encuadernaciones para libros ubicados en los archivos de la catedral y de la parroquia de san Andrés. Algunas hipótesis que pretenden explicar tal acontecimiento son:

1) ¿Quizás se trataban de pergaminos desechados en una guenizá que, tras la expulsión, aprovecharían los encuadernadores? Parece bastante improbable ya que los textos depositados en la guenizá eran considerados inservibles para la lectura o porque el material en el que se escribieron no estaba en condiciones adecuadas. Como se apreciará más adelante en las fotografías, los documentos tienen un buen estado de conservación.

2) ¿Existe la remota posibilidad de que el rabino de la aljama se convirtiera y le permitieran conservar los libros bíblicos hasta su muerte, pues no dejan de ser parte del Antiguo Testamento? En este improbable caso, hipotetizamos que se pudieran haber respetado los textos hebreos mientras viviera el rabino converso, pero tras su fallecimiento cambiara el parecer de los cristianos. Otra opción es que los hubiera tenido que entregar como muestra de su sincera conversión, aunque se tratasen de textos también sagrados para los cristianos que se los requiriesen.

3) ¿Es posible que hubieran estado escondidos en casa de algún falso converso pero que fueron encontrados? Así, bien el obispo a

${ }^{10}$ Cf. Juan Manuel Tudanca Casero y Carlos López de Calle Cámara, «Entorno urbanístico de la catedral de Calahorra: apuntes para una valoración patrimonial», en Investigación humanística y científica en La Rioja: homenaje a Julio Luis Fernández Sevilla y Mayela Balmaseda Aróspide (Logroño: Instituto de Estudios Riojanos, 2000) págs. 171-192: 183. 
través de la curia o bien la Inquisición ${ }^{11}$ disponían destruirlos o que sirvieran para encuadernación. Nótese que tanto el obispo diocesano como el tribunal de la Inquisición (hasta finales del s. XV cuando se trasladó a Logroño) tenían en Calahorra su sede episcopal y su tribunal de justicia, respectivamente. No obstante, la mayoría de los obispos de los ss. XIV-XV no vivieron presencialmente en la ciudad bimilenaria ${ }^{12}$. Además, era conocida en la época la rivalidad entre inquisidores y obispos ${ }^{13}$. Consideramos esta opción como la más factible, ya que los procesos que ambos llevaban a cabo se ordenaban y cosían formando un expediente. Así, buscando la óptima conservación del mismo, se usaba una hoja inicial y final que protegiera los documentos ${ }^{14}$. Argumento que sustenta esta postura son las palabras «1500 alforín $1500 »{ }^{15}$ en el fragmento de Éxodo, que demostraría que tales páginas del Pentateuco fueron inicialmente utilizadas para custodiar y proteger una serie de cuentas agrarias.

Esta última propuesta no es ajena al quehacer de la época medieval europea. De hecho, era bastante común hacer uso de legajos y papiros de libros hebreos para utilizarlos como cubiertas y lomos de otras obras, cartivanas, refuerzos en encuadernaciones... Allá donde las comunidades judías se dedicaban a actividades intelectuales o constituían un grueso importante de la población local, se han hallado numerosos manuscritos, especialmente en Italia y España ${ }^{16}$.

11 Cf. Cantera Montenegro, «Los últimos tiempos de la presencia judía en Calahorra y La Rioja», pág. 75.

12 Cf. Sárnz Ripa, Sedes episcopales de La Rioja, págs. 128-563.

13 Cf. Javier del Barco del Barco e Ignacio Panizo Santos, «Fragmentos de incunables hebreos en documentos inquisitoriales del Tribunal de Calahorra-Logroño», Huarte de San Juan. Geografia e Historia 17 (2010) págs. 295-308: 297.

14 Cf. Del Barco del Barco y Panizo Santos, «Fragmentos de incunables hebreos en documentos inquisitoriales del Tribunal de Calahorra-Logroño», pág. 300.

15 Libro de cuentas que relacionaba el grano cosechado por cada familia con el fin de controlar las cantidades que hubieran de pagar como diezmo.

16 En este sentido, el proyecto "Books within Books: Hebrew Fragments in European Libraries" se dedica, precisamente, a la recopilación y estudio de tales fragmentos en Europa, Estados Unidos e Israel. 


\section{Fragmento de ÉXODO}

El archivo parroquial de san Andrés, junto con el de la catedral, es uno de los más antiguos de Calahorra. De hecho, funcionaba en conjunto con el de la parroquia de Santiago el Real. Los documentos más antiguos que se conservan datan de finales del s. XI, lo que hace de él una de las fuentes más sustanciosas para conocer la historia de la ciudad.

Como todo archivo que se precie, existía un orden en la catalogación. No obstante, en la década de 1960, Fernando Bujanda, prestigioso archivero ${ }^{17}$ de la catedral de Calahorra, puso en orden y comprobó la catalogación, haciendo un breve estudio de los documentos. De este modo, metió los libros y legajos más importantes en cajas de madera.

Acerca de esta labor, E. Sáinz Ripa afirma:

[F. Bujanda] Elaboró también la Colección Diplomática de la parroquia de San Andrés de Calahorra. Hasta ahora inédita, queda mecanografiada en el legado documental de Bujanda. Se trata de un trabajo de documentalista sobre los fondos de esta parroquia calagurritana. Bujanda catalogó sus documentos que registra bajo 333 signaturas ${ }^{18}$.

Es precisamente en la última signatura donde se realizó el hallazgo de una página del Éxodo de una Biblia hebrea. Fue Julián Cantera Orive, arcediano de la catedral, quien la dató en el s. xIV e identificó el texto que contenía dejando la siguiente anotación mecanografiada cosida al pergamino:

Signatura 333

Siglo XIV

Pergamino hebreo, dos folios, parte de una Biblia. Contienen el primero parte del Éxodo, XXX,23 a XXXI,18. El segundo, parte del

${ }^{17}$ Un ejemplo de su labor -en este caso, respecto a la organización del archivo catedralicio, cuyos documentos son complementarios de aquellos de la parroquia de san Andrés, tal como afirma el propio Bujanda ( $c f$. Eliseo SÁrnz RIPA, «Fernando Bujanda, investigador de la historia de Calahorra», Kalakorikos 3 [1998] págs. 151-168: 155)- se encuentra publicado en Fernando Bujanda, «Archivo catedral de Calahorra», Berceo 77 (1965) págs. 417-478, 78 (1968) págs. 29-80 y 79 (1968) págs. 135-146.

18 SÁinZ RIPA, «Fernando Bujanda, investigador de la historia de Calahorra», pág. 155. Actualmente, dicha colección diplomática está en proceso de publicación, $c f$. Pedro Pérez CARAzo, Colección diplomática medieval de la iglesia de San Andrés de Calahorra (Logroño: Instituto de Estudios Riojanos, 2021). 
mismo Libro, XXVI,24 a XXVII,16. (D. Julián Cantera, 25 de octubre de 1.935).

En el margen superior sobre la columna izquierda de la portada de la encuadernación se lee «1500 alforín 1500». Por tanto, si bien J.Cantera no dejó por escrito de qué libro extrajo el documento, es muy posible que el pergamino sirviera como alforín que iniciara dicho año.

En los márgenes superior e inferior de todo el documento hay una serie de anotaciones posteriores al texto hebreo, pues son palabras castellanas escritas una vez el pergamino dejó de estar en manos judías. Nótese que no hay anotaciones hebreas marginales, como Masora. Igualmente, en el margen lateral derecho de la contraportada de la encuadernación están dibujados dos soles con las inscripciones internas: «IHS» en el izquierdo y «MA» en el derecho. Esto implica una mano cristiana en el documento, pues aluden a Jesucristo y a María, su madre. Muy probablemente, quien escribiera el alforín fuera un creyente cristiano que dejaría su marca personal en un texto originalmente judío. Además, al final se puede leer «a(nno) d(omini) n(ostri) 1505». ¿Es posible que la contabilidad del alforín abarcara hasta ese año?

Respecto a su análisis formal ${ }^{19}$, se trata de un texto escrito en tinta negra que se ha decolorado en ciertas secciones por el paso del tiempo. Así, no se aprecian difuminaciones de tinta ni ennegrecimiento por el paso del tiempo. El estado de conservación es óptimo, puesto que la materia escriptoria es de excelente calidad, probablemente de procedencia caprina. La letra es de tipo cuadrada sefardí ${ }^{20}$.

${ }^{19}$ La estructura de la presentación de los manuscritos, tanto de Ex como de Est, siguen a Judith Kogel, Sur les traces de la bibliothèque médiévale des Juifs de Colmar. Reconstitution à partir des fragments conservés dans les reliures d'incunables European Genizah Texts and Studies, vol. 3, Studies in Jewish History and Culture 56 (LeidenBoston: Brill, 2019) y a Andreas LeHNARDT, «The Binding Fragments of Madras Tanhuma (Buber) from the Municipal Library of Trier», en Binding between Sister Religions. Studies of Jewish and Christian Scriptures Offered in Honor of Prof. John T. Townsend, ed. Isaac Kalimi (Leiden-Boston: Brill, 2016) págs. 217-238.

${ }^{20}$ Un análisis de la letra conforme a Edna ENGEL, «Script, History of Development», en Encyclopedia of Hebrew Lan-guage and Linguistics, vol. 3, ed. Geoffrey KHAN (Leiden-Boston: Brill 2013) págs. 485-502: 490-492, coincide con la datación propuesta por J. Cantera. Así, de acuerdo con Engel, el documento pudiera datar entre los ss. XIII-XIV. Si bien en el s. XIV los judíos calagurritanos tenían prácticamente los mismos derechos 
Respecto a las características externas, podemos afirmar que los folios formaban parte de un una Biblia hebrea redactada en forma de libro. De hecho, en la parte interna se aprecian claramente una serie de agujeros equidistantes por los cuales un hilo habría unido todas las páginas. Otro argumento es que dicha parte está ligeramente más oscurecida que el resto del documento. Finalmente, se podría concluir que hubiera otra página interior que abarcaría Ex 27,17-30,23a en dos folios con dos columnas en cada una.

Desplegado, el documento tiene una longitud total de 440 $\mathrm{mm}(220 \mathrm{~mm}$ por cara) y una altura de $315 \mathrm{~mm}$. Consta de cuatro columnas paralelas escritas por cada cara de unos $205 \mathrm{~mm}$ de altura por $85 \mathrm{~mm}$ de anchura. El margen superior es de $30-35 \mathrm{~mm}$ y el inferior de $70-75 \mathrm{~mm}$; mientras que el intercolumnado mide $20 \mathrm{~mm}$.

Se aprecian líneas rectrices, más fácilmente perceptibles las paralelas para escribir el cuerpo del texto. Son ligeros arañazos que sirven como guía a las letras, que se colocan a tres cuartos de altura, dejando un mayor margen de separación en la parte inferior de la línea rectora. No se aprecian perforaciones en los márgenes exteriores o interiores para el trazado de dichas líneas.

Hay 21 líneas de texto cuerpo por página, distando $5 \mathrm{~mm}$ en vertical una línea de la siguiente. Si bien el espaciado es regular en todo el cuerpo, sucede que al terminar algunas líneas se alarga la letra para conseguir la justificación. Todas las líneas son paralelas, sin tendencia a curvarse. Por su parte, las letras suelen estar suficientemente separadas para una rápida y correcta lectura. Aunque algunas se aproximan hasta el punto de tocarse por la parte superior, no se observan ligaduras. Los pies tienden a inclinarse ligeramente hacia la derecha, aunque también los hay perpendiculares a la línea base. Los ángulos de las letras se suavizan curvándose de manera convexa, por lo que apenas se aprecian ángulos rectos.

El texto es perfectamente legible. Asimismo, está en gran parte vocalizado (tiberiense), aunque en ciertas secciones se haya perdido.

y privilegios que los cristianos, esta situación pudiera haber favorecido el desarrollo literario e intelectual. De hecho, muestra una gran similitud con el estilo de letra de Ms L44a, producido en Toledo en el s. XIII, aunque la calidad es inferior a la Hagadá de Barcelona del s. XIV. Por tanto, consideramos más plausible catalogarlo, tal como afirmó J. Cantera, del s. XIv. 
Procedamos a un breve análisis siguiendo el orden del texto bíblico:

- Cara trasera externa de la encuadernación: se corresponde con el inicio del texto, leyendo en la columna derecha Ex 26,24b-31a sin haber variantes textuales ${ }^{21}$. Por su parte, la izquierda lee Ex 26,31a37a. Hay dos términos que varían al usar hólem en vez de vav hólem, aunque el primero es corregido en una anotación superíndice. A saber, עמדי (v.32) y ותלעת (v.36). Asimismo, están omitidas la ונתתה (v.33); y la vav hólem de ותולעת (v.36). De Rossi 22 propone תעשה en el v.31b, pero lo leen pocos manuscritos.

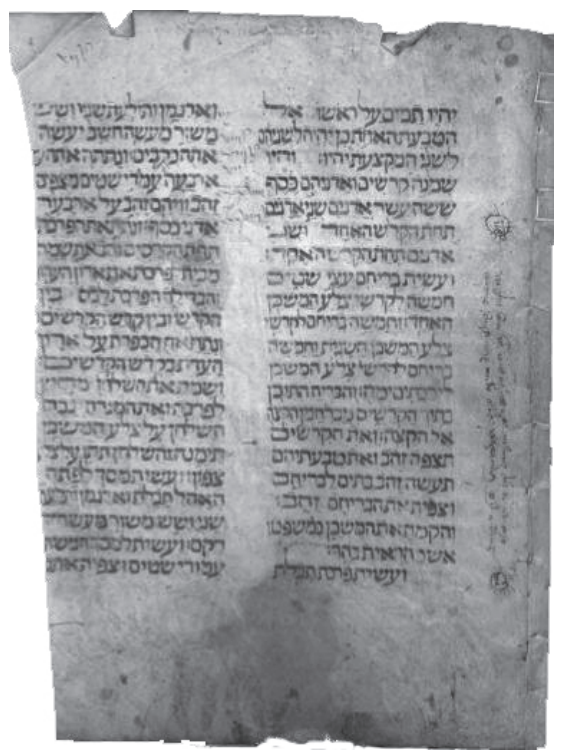

Imagen 1: Ex Trasera externa

21 Todas las variantes textuales a las que se aluda a lo largo del estudio sobre el texto de Ex son en referencia a la Biblia Hebraica Suttgartensia (BHS). Si bien es cierto que existen otras obras con las que comparar el texto bíblico, como Benjamin KenNICotT, Vetus Testamentum Hebraicum: cum variis lectionibus, vol. 1 (Oxonii: Typographeo Clarendoniana, 1776) y Giovanni Bernardo de Rossi, Variae Lectionis Veteris Testamenti Ex Immensa Mss. Editorumq: Codicum Congerie Haustae Et Ad Samar: Textum, Ad Vetustiss: Versiones, Ad Accuratiores Sacrae Criticae Fontea Ac Lege Examinatae Opera Ac Studio Johannis Bern, vol. 1 (Parmae: Regio Typographeo, 1784), consideraremos preferentemente la BHS. No obstante, allá donde difieran, se valorarán las variantes de las otras obras mencionadas.

22 Cf. DE Rossi, Variae Lectionis Veteris Testamenti, pág. 72. 
- Cara interna derecha de la encuadernación: la columna derecha lee Ex 26,37a-27,8 y no tiene variantes textuales. La izquierda lee Ex 27,8-16a. Aunque no haya variantes, es de notar el final de la tercera línea, donde se aprecian ligeros raspados horizontales con un hierro afilado con el fin de borrar lo inicialmente escrito. De hecho, dicha sobrescritura es patente, porque la tinta todavía permanece negra; mientras que el resto del documento ha adquirido un tono ocre debido al paso del tiempo. Por tanto, lo lógico es pensar en una intervención de una segunda mano distinta al amanuense original. Argumento de ello es que la línea sale pronunciadamente de la columna, las letras no siguen una estabilidad horizontal sino que parecen "bailar" y está omitida la תימנה (v.9b). ¿Quizá porque coincidiría con el canto del libro, estando dibujada en la página interior que abarcaría Ex 26,17-30,23a?

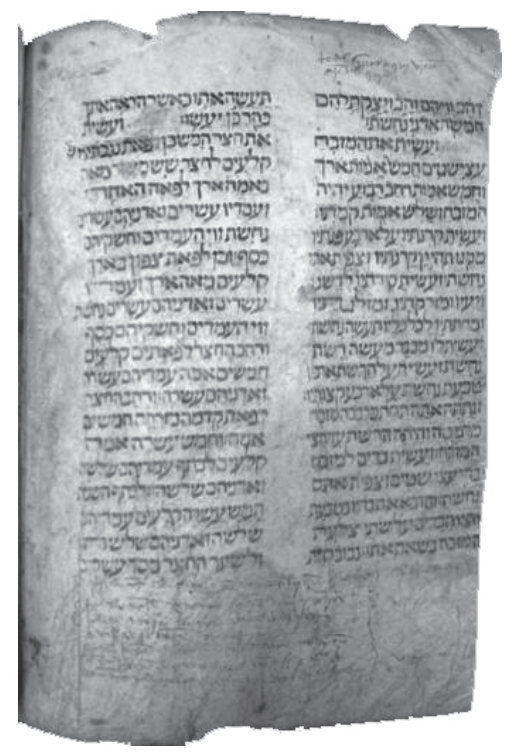

Imagen 2: Ex Interna derecha

- Cara interna izquierda de la encuadernación: se lee Ex 30,23a-33 en la columna derecha y Ex 30,34-31,4 en la izquierda, sin nin- 
guna variante de lectura en los textos. De Rossi ${ }^{23}$ propone omitir la vav inicial del v.27 y del v.4, pero Kennicott y $B H S$ las leen. Asimismo, propone ${ }^{24}$ en el v.34 ויאמר pero Kennicott y BHS leen la segunda.

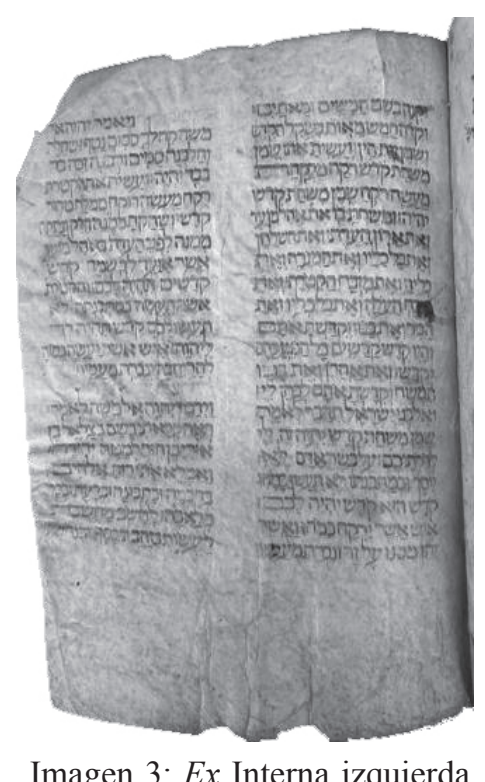

Imagen 3: Ex Interna izquierda

- Cara delantera externa de la encuadernación: la primera columna lee Ex 31,5-13a y la izquierda Ex 31,13b-18. En el v.6 hay una diptografía al repetirse la partícula de objeto directo en el final de la tercera línea; y en el v.13 el amanuense olvidó la última letra de לדרתיכם y lo corrigió colocándola en superíndice. De Rossi ${ }^{25}$ propone introducir לשרת בקדש en el v.10, pero BHS y Kennicott no lo leen. De hecho, solamente lo leen unos pocos manuscritos.

\footnotetext{
${ }^{23} C f$. DE Rossi, Variae Lectionis Veteris Testamenti, págs. 73-74.

${ }^{24}$ Cf. DE Rossi, Variae Lectionis Veteris Testamenti, pág. 74.

${ }^{25}$ Cf. DE Rossi, Variae Lectionis Veteris Testamenti, pág. 75.
} 


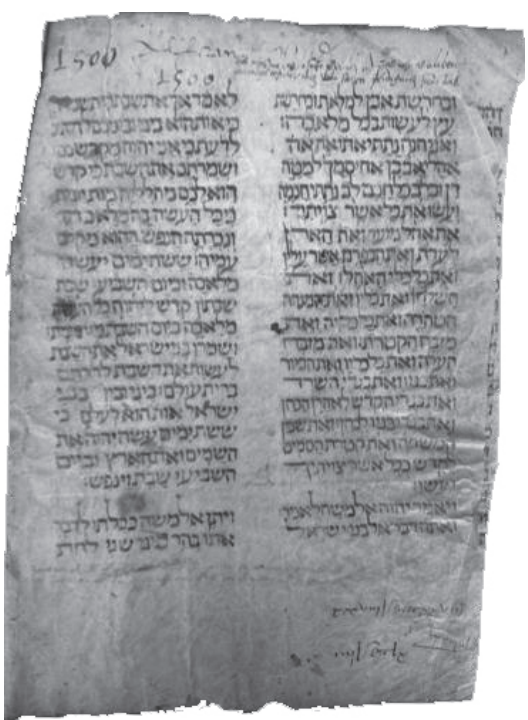

Imagen 4: Ex Delantera externa

\section{Fragmento de Ester}

Durante el mes de julio de 2020, se puso nuevamente en orden el archivo de la parroquia de S. Andrés de Calahorra, guardándose en más de 250 cajas de cartón nuevas, específicamente construidas y diseñadas para tal efecto. Tal labor de revisión fue llevada a cabo por Javier Fernández Cascante, párroco de san Andrés y canónigo de la catedral, junto con dos seminaristas pertenecientes al Seminario Internacional Bidasoa (Pamplona) que pasaban con dicho sacerdote su período estival.

En este contexto, en un libro titulado «De la Cofradía de Santiago y san Andrés» y que comienza en 1514 fueron hallados cuatro fragmentos más de otra Biblia hebrea. Es de notar que los pergaminos de este nuevo hallazgo difieren de la página encontrada por F. Bujanda, por lo que se trataría de una Biblia diversa. J. Fernández afirmó que los dos fragmentos más largos estaban sueltos, mientras que el otro par, los más pequeños, estaban unidos sirviendo como refuerzo del canto del libro.

En lo concerniente al análisis formal, se trata de cuatro fragmentos escritos en tinta negra especialmente oscurecidos en los bordes por el 
paso del tiempo, humedades y haber adquirido tonos y letras de otros documentos a los cuales han estado solapados y que han sido afectados por la temperatura. No obstante, el texto se puede leer adecuadamente, salvo algunas secciones que limitan con los bordes, especialmente en los dos fragmentos más alargados. El estado de conservación es bueno, porque la piel es de cabrito, de tono homogéneo y buena calidad. Sin embargo, hay ciertas roturas laterales y arrugas, pues los fragmentos fueron recortados y plegados para encuadernar el libro de la cofradía.

Las grafías hebreas son de tipo cuadrada sefardí y, probablemente, se trate de un texto del s. xIV. Razón de ello son las grandes similitudes con el tipo de letra del pergamino de Ex y con la descripción de la evolución epigráfica de E. Engel ${ }^{26}$, pues todavía no ha iniciado el proceso de decadencia propio del s. Xv, y la situación socio-cultural para la producción de manuscritos en dicha época.

Todos los fragmentos pertenecen al libro de Ester de la misma Biblia y están escritos por ambas caras, leyéndose en conjunto Est 3,7-4,14. Presumiblemente sería parte de un códice en su origen por la forma cuadrada de la página y la distribución de las masoras, pero los recortes en los márgenes y el deterioro causado por la humedad impiden pruebas concluyentes.

La obtención de los fragmentos responde a los siguientes cortes: la columna derecha fue recortada a lo ancho (fragmentos 1-2) y la izquierda en vertical (fragmentos 3-4). Representación gráfica de la página original:

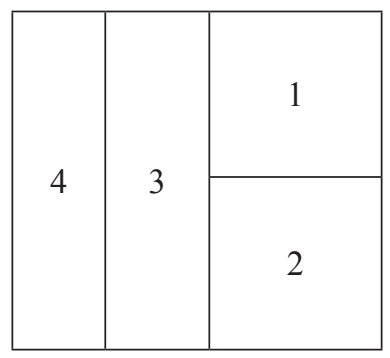

Respecto a las dimensiones, el fragmento 1 tiene una altura de $85 \mathrm{~mm}$ $\mathrm{y}$ una anchura de $75 \mathrm{~mm}$. Junto al fragmento 2 formaban parte original-

${ }^{26} C f$. EnGEL, «Script, History and Development», págs. 490-492. Por tanto, nuevamente coincide con el tipo de letra desa-rrollado en Ms L44a, asimismo con su diseño de formato, y con aquel de la Hagadá de Barcelona. 
mente de la misma columna, la derecha, siendo el 1 la parte superior y el 2 la inferior. El tamaño del fragmento 2 es de $107 \mathrm{~mm}$ de alto por $55 \mathrm{~mm}$ de ancho. El fragmento 3 mide $219 \mathrm{~mm}$ de alto por $65 \mathrm{~mm}$ de ancho y, junto al fragmento 4 , conformaban originalmente una misma columna que ha sido cortada verticalmente. De este modo, el fragmento 3 se corresponde con la parte derecha de la columna y el 4 con la izquierda. La ausencia de palabras entre ambos fragmentos dificulta la lectura y la posibilidad de identificar variantes. La parte derecha del fragmento 3 está oscurecida porque se usó como canto a la hora de encuadernar. Las dimensiones del fragmento 4 son $215 \mathrm{~mm}$ de altura y $60 \mathrm{~mm}$ de anchura.

De este modo, los cuatro fragmentos conforman originalmente una misma página de forma cuadrada que tiene alrededor de $220 \mathrm{~mm}$ de base. Así, el texto hebreo se distribuye en dos columnas paralelas de unos $70 \mathrm{~mm}$ de anchura y $150 \mathrm{~mm}$ de altura aproximadamente. Los márgenes laterales tienen entre $15-35 \mathrm{~mm}$ de longitud. Por su parte, los márgenes superiores alcanzan los $35 \mathrm{~mm}$ y el central o intercolumnado que separaría ambas columnas se estima en 10-20mm.

No se aprecian líneas rectrices y, de hecho, pese a la pretensión de una redacción lineal y justificada, hay una ligera tendencia a crear un pequeño éntasis hacia la parte superior en la parte central de cada columna. Este hecho es bastante perceptible en la combinación de los fragmentos 3 y 4 .

Hay 19 líneas de texto cuerpo por página, siendo la altura de las letras de $5 \mathrm{~mm}$. La proporcionalidad y el espaciado entre palabras y letras es regular, excepto cuando a final de columna se tiene necesidad de justificar. Si bien el pie de letra tiende a inclinarse ligeramente a la derecha, los ductus superiores son perpendiculares a la base de la letra. Las letras no son angulosas, sino que se curvan de manera convexa, más radicalmente que en el texto de Ex. Da la sensación de que el escriba hubiera realizado el texto deprisa, pues el cálamo tiene prácticamente el mismo grosor en todos los trazos, ya que no son finos ni delicados. También cabe afirmar que el texto está vocalizado (tiberiense).

Finalmente, cabe destacar en los márgenes exteriores una serie de anotaciones de menor tamaño, que no están vocalizadas, a diferencia del texto bíblico. Son fácilmente apreciables en los márgenes superiores e inferiores (masora magna) de todos los fragmentos y en los laterales (ma- 
sora parva) de los fragmentos 1 recto, 3 recto, 3 vuelto y 4 vuelto. No obstante, no todas estas anotaciones se conservan con claridad debido al corrimiento o desaparición de la tinta y al minúsculo tamaño de la letra.

Procedamos a un breve análisis de los diversos fragmentos:

- Fragmento 1:

En el recto se lee Est 3,7b-9b. Si bien no hay variantes textuales ${ }^{27}$, la parte izquierda está deteriorada al haber formado parte del lomo del libro de la cofradía y recortada porque falta la última palabra de cada línea por los recortes.

El vuelto lee Est 4,8-11a. En el v.10 aparece la preposición על על vez de en contraste con BHS y Kennicott ${ }^{28}$. ¿Quizás por influencia del v.5? Además, lee como hólem en vez de vav hólem el término לבוא (v.8).

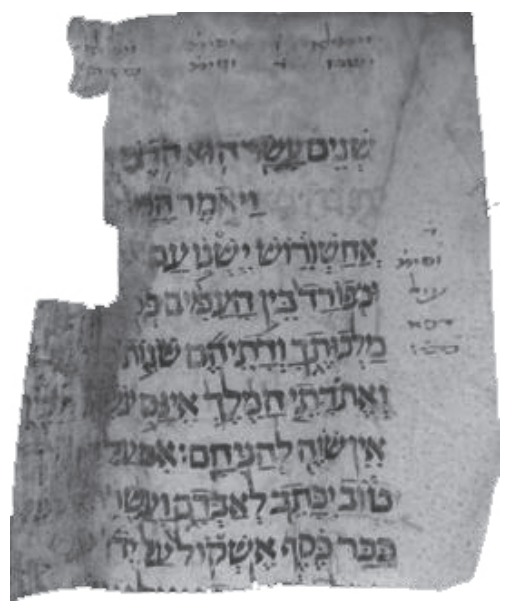

Imagen 5: Est frag. 1 recto

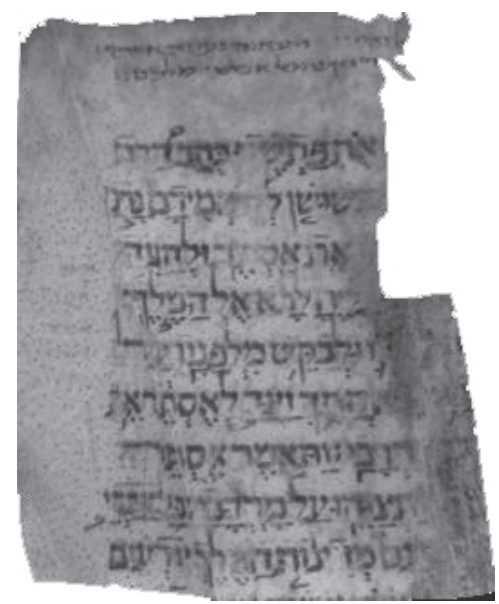

Imagen 6: Est frag. 1 vuelto

27 Todas las variantes textuales a las que se aluda a lo largo del estudio sobre el texto de Est son en referencia a la Biblia Hebraica Stuttgartensia (BHS). Si bien es cierto que existen otras obras con las que comparar el texto bíblico, como Kennicott, Vetus Testamentum Hebraicum; consideraremos preferentemente la BHS. Por su parte, DE Rossi, Variae Lectionis Veteris Testamenti, y Dominique BARTHÉLÉMY y Alexander Reinard Hulst, Critique textuelle de l'Ancien Testament. 1. Josué, Juges, Ruth, Samuel, Rois, Chroniques, Esdras, Néhémie, Esther (Göttingen: Vandenhoeck \& Ruprecht, 1982) no difieren de $B H S$.

${ }^{28}$ Cf. KennicotT, Vetus Testamentum Hebraicum, pág. 566. 
- Fragmento 2:

El recto lee Est 3,10-12b. Aparecen dos variantes similares ${ }^{29}$ en las que, al vocalizar, se hace uso de hólem en vez de vav hólem. Así, en el v.10 se lee צרלושה y en el v.12. El recorte sufrido en el fragmento 1 entra más en el texto, llegando a cortar las dos últimas palabras de cada columna. Además, entre ambos fragmentos falta una línea que se correspondería con el final del v.9.

Por su parte, el vuelto lee Est 4,11b-14a. No se aprecian variantes textuales, pero la parte superior muestra una lectura difícil y algunas líneas están totalmente difuminadas.

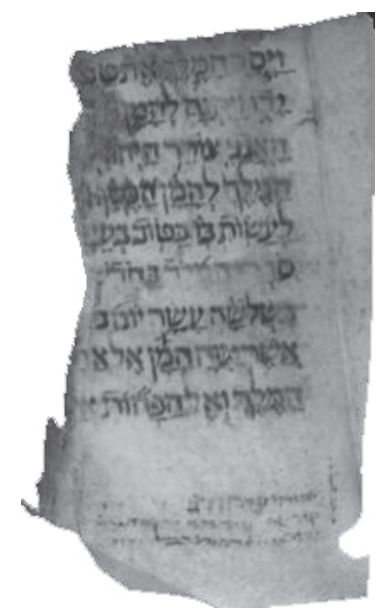

Imagen 7: Est frag. 2 recto

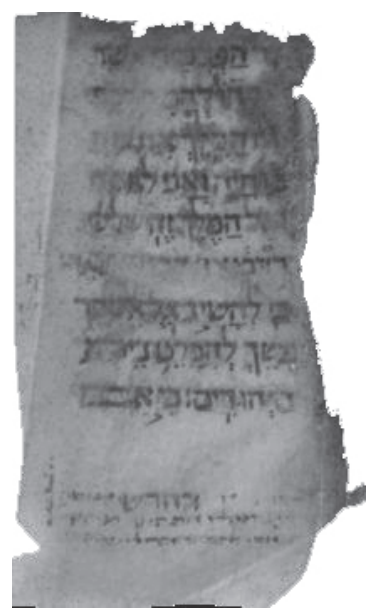

Imagen 8: Est frag. 2 vuelto

- Fragmento 3:

El recto lee Est 3,12c-4,1. Nuevamente, al vocalizar se hace uso de hólem en vez de vav hólem ${ }^{30}$ en בשלושה (v.13). El recorte diagonal es profundo, pues al final de la columna apenas se leen un par de términos.

\footnotetext{
${ }^{29}$ Cf. Kennicott, Vetus Testamentum Hebraicum, pág. 565.
}

30 Cf. Kennicott, Vetus Testamentum Hebraicum, pág. 565. 
A su vez, el vuelto lee Est 4,1e-7b. Se lee ותבאינח en el v.4, mientras que $B H S$ y Kennicott lo leen con vav hólem. Además, Kennicott ${ }^{31}$ lee con vav hólem גדולה (v.1) frente al fragmento y BHS que lo leen con hólem.

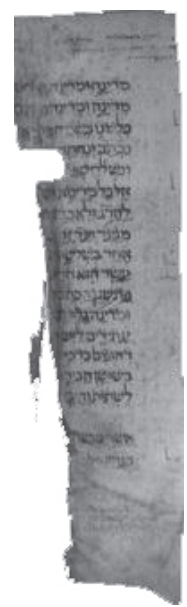

Imagen 9: Est frag. 3 recto

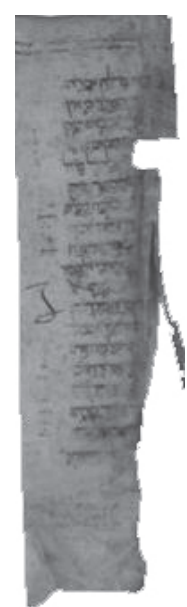

Imagen 10: Est frag. 3 vuelto

- Fragmento 4:

El recto lee Est 3,12d-4,1. No se leen variantes. La parte izquierda está ennegrecida porque se usó como canto del libro de la cofradía. Esta es la razón por la que tiene algunas letras hebreas perfectamente legibles, porque se ha calcado de otro texto usado también como encuadernación.

Por otro lado, el vuelto lee Est 4,1d-7b. El escriba otra vez sustituye vav hólem por hólem en לבוא (v.3).

\footnotetext{
31 Cf. Kennicott, Vetus Testamentum Hebraicum, pág. 565.
} 


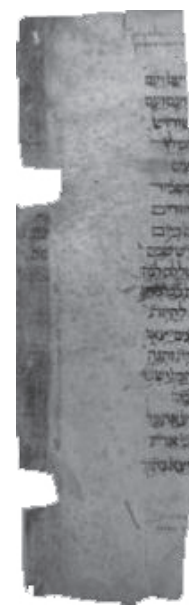

Imagen 11: Est frag. 4 recto

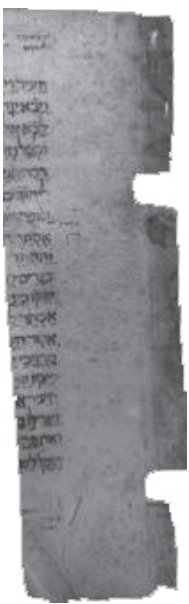

Imagen 12: Est frag. 4 vuelto

\section{CONCLUSIÓN}

El hallazgo de los cuatro fragmentos del libro de Ester y el análisis del pergamino del Éxodo dan mayor peso histórico a la importancia de la judería calagurritana a finales de la Baja Edad Media. De hecho, se trata de nuevas pruebas para afirmar el desarrollo intelectual, cultural y religioso de los judíos calagurritanos en los Ss. XIV-XV. Asimismo, la forma en la que nos han llegado los fragmentos de Est es indicativa también de la actividad cristiana de la época y, en cierto modo, de la relación entre los poderes eclesiásticos y civiles con los hebreos creyentes. En definitiva, el conjunto de los textos hebreos conservados en Calahorra puede aportar una interesante información sobre la historia local de la ciudad.

Tratándose de dos documentos de similar datación (s. XIV), las diferencias entre ambos son notables. La existencia de masora en Est y su ausencia en Ex indican que ambos textos se usaron para fines diversos. Así, es probable que la diferenciación responda a dos propietarios distintos. Este hecho señala a su vez el próspero poder económico judío en dicho siglo.

Recibido: 30/09/2020

Aceptado: 04/04/2021 